\section{Flowers born to blush unseen?}

Ten years ago, I was a member of a team that went to visit a school in a far outlying location of the Cabo del Dado Province in northern Mozambique, the home of more elephants than had (at the time) been counted. The team included one of my then colleagues, and three associates from the Aga Khan Foundation who were based in the town of Pemba.

To reach the school, my colleague and I flew for $2 \mathrm{~h}$ from Johannesburg to Pemba, spent a night there, and were then driven for $3 \mathrm{~h}$ in a four-wheel 'monster' to reach the school, located in the middle of the Quirimbas National Park, which stretches from inland areas to the Mozambican coastline.

This Leader is not, however, about the school, but about the lunch we were served - a salad, made of leaves that were entirely foreign to me, and served with a peanut sauce. I asked a teacher from the school what it was we were eating and he said, with great surprise at my ignorance, 'Moringa, of course'. I ate on, without disappointment - the salad was delicious.

On returning to South Africa, I looked for details about Moringa oleifera and discovered that its leaves are comparable to Andean quinoa grain: a remarkably nutritious food source that is an antioxidant, is rich in amino acids, and which contains, amongst other nutrients, calcium, magnesium, iron, iodine, lutein, zinc and vitamins A and B3.

It is not surprising, then, that all of 10 years later, the South African Journal of Science has received an unexpected number of papers that provide research findings on the nutritional and/or health values of a wide variety of indigenous, or indigenised, African plants. Many of the papers were derived from the theses and dissertations of postgraduate students who studied at universities in Africa. Not all of the manuscripts have been suitable for publication, but many that have been, have dealt with various uses of Moringa oleifera leaves, bark and roots, with emphasis not only on nutrition but also on the production and uses of oils and creams from various parts of the tree.

The papers most recently published speak to a range of issues, although the three areas most frequently addressed are nutritional value, food security and medicinal properties. As the papers are all about plants, these areas of focus are not surprising, although the range of research approaches and findings are remarkably diverse.

While they do not intentionally set out to do so, two papers reveal the opposite sides of the debates around 'indigenous knowledge'. In a paper dealing with sweet potatoes' ('indigenised' since the 1500s), the authors' focus is on nutrition and drought resistance - both critical in contributing to food security in times of drought, such as much of the country faces at present. On the other hand, the authors of a paper on wild vegetables ${ }^{2}$ (Corchorus olitorius and Amaranthus cruentus) conclude that although claims have been made that these particular wild vegetables have superior micronutrient content to that of 'exotic' vegetables, this is demonstrably not the case. In the first case, indigenous knowledge is confirmed - sweet potatoes, a staple source of food, are suited to our climate, and to climatic changes. Conventional wisdom prevails. In the second case, however, wild vegetables are shown not to have properties superior to 'exotics'.

As might be expected, a number of papers focus on the medicinal or health value of plants. The most unusual of these, 'Plants, people and health: Three disciplines at work in Namaqualand'3 is a paper that investigates not just plants but also multidisciplinary approaches to research. The theoretical focus of the paper is multidisciplinary while the subject focus is medicinal plants found in Namaqualand.

\section{The main conclusion of the paper is that}

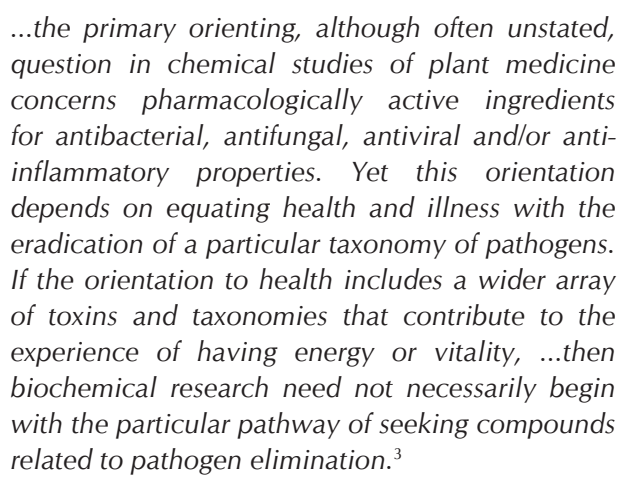

Sadly, the paper does not go on to suggest what the other 'particular pathways' might possibly be. While the earlier papers suggested contested notions of indigenous knowledge, this paper leaves the understanding of plants in a rather ambiguous position.

Two other plant-medicinal papers proceed and conclude from what some scholars might consider to be a more limited (or, in the views of some, simply wrong), empiricist position - but they have the advantage of offering results that can be tested and readily contested.

The researchers ${ }^{4}$ who studied the mutagenic and antioxidant effects of uMakhonya ${ }^{\circledR}$, advocated by traditional healers for many years, concluded that it could well have value in treating the symptoms of HIV/AIDS. Similarly, a study ${ }^{5}$ of 48 South African medicinal plants - whose antimutagenic and antioxidant properties might be effective in treating acne - concluded that, used alone or in combination with one another, the extracts have considerable potential in the successful treatment of skin ailments.

Their intrinsic values apart, these and related papers have two other contributions to make. Firstly, they draw attention to the debate around indigenous knowledge, some of which is of enormous importance and value; and some of which might well be matters of folklore. Secondly, they are powerful reminders of Einstein's often forgotten, but challenging, comment that we cannot solve our problems with the same thinking we used when we created them.

\section{References}

1. Motsa NM, Modi AT, Mabhaudhi T. Sweet potato (Ipomoea batatas L.) as a drought tolerant and food security crop. S Afr J Sci. 2015;111(11/12), Art. \#2014-0252, 8 pages. http://dx.doi.org/10.17159/sajs.2015/20140252

2. Mavengahama S, De Clercq WP, McLachlan M. Trace element composition of two wild vegetables in response to soil-applied micronutrients. S Afr $\mathrm{J}$ Sci. 2014;110(9/10), Art. \#2013-0339, 5 pages. http://dx.doi.org/10.1590/ sajs.2014/20130339

3. Green L, Gammon DW, Hoffman MT, Cohen J, Hilgart A, Morrell RG, et al. Plants, people and health: Three disciplines at work in Namaqualand. S Afr J Sci. 2015;111(9/10), Art. \#2014-0276, 12 pages. http://dx.doi. org/10.17159/sajs.2015/20140276

4. Ngcobo M, Gqaleni N, Ndlovu V. Antimutagenic and antioxidant effects of a South African traditional formulation used as an immune booster. S Afr J Sci. 2016;112(3/4), Art. \#2015-0152, 7 pages. http://dx.doi.org/10.17159/ sajs.2016/20150152

5. Sharma R, Lall N. Antibacterial, antioxidant activities and cytotoxicity of plants against Propionibacterium acnes. S Afr J Sci. 2014;110(11/12), Art. \#20130293, 8 pages. http://dx.doi.org/10.1590/sajs.2014/20130293 